\title{
REVITALISATION OF HISTORIC PUBLIC CEMETERIES IN CENTRAL ZONES OF URBAN AREAS
}

\author{
IVONA DLÁBIKOVÁ, KLÁRA FROLÍKOVÁ-PALÁNOVÁ \& MARTINA PEŘINKOVÁ \\ Department of Urban Construction, Technical University of Ostrava, Czech Republic
}

\begin{abstract}
Historic public cemeteries, thanks to their social function, are an integral part of urban areas. They exemplify a relationship and respect for values which were created by previous generations. A relatively large extent of the historic public cemeteries, founded during the 18th and 19th century, have been preserved until now in the Czech Republic. Some of them could be extended to fulfil their social function to this day. But some of them, thanks to fast development, have appeared in central zones of urban areas and therefore have ceased to fulfil their original function. Other cemeteries ceased their activity and instead, housing estates, factories or parks were created. In some cases, the original ethical principles were not respected. Questions arise here: what is and what will be the fate of historic public cemeteries which cease to fulfil their function? How will the outcome be handled by representatives, investors and conservationists? The aim of this article is to explain the influence of urban structures on cemeteries as well as how cemeteries influence urban structures and adaptation of these areas to meet its current needs and the needs of the society. It will also give a prognosis for the further development of cemeteries within towns.
\end{abstract}

Keywords: cemetery, urban area, Czech Republic, grave, cemetery wall.

\section{INTRODUCTION}

Cemeteries are places built and shaped by the gradual adding of new graves over a long time. Their location is thus formed by the rules and laws from the past, earlier than other surrounding buildings were built. Cemeteries have experienced different time eras and styles; they are like time capsules [1]. In cities, cemeteries are often attached to a park or garden or they alone create a garden among which graves are located. Each cemetery is different, not due to poor arrangement, but because their location within the city is different, and therefore they all meet different needs. This is essential for the proper functioning and operation of cemeteries.

The prognosis for individual cemeteries cannot be determined in general: each of them is unique and fills different needs in the city in terms of certain size, location, faith and links to the funeral buildings and other parts of the city. That is why we will focus on three specific cemeteries in a European city and find out how they are fighting for their place in the present time of growing infrastructure and overcrowding. The following examples can offer examples of ideas for revitalising and renewing other cemeteries.

\section{HISTORY}

First row graves were located outside residential areas (on nearby roads, etc.), but with the onset of Christianity they moved closer to homes or became part of the church (nearby or within it). In the 2nd century, grave burial became highly popular (as a legacy to pre-Christian culture and Christianity) [1]. In 789 Charles the Great issued a decree that prohibited the cremation of bodies, with a punishment of the death penalty. This ban was respected in Europe for more than one-thousand years. From the 11th century, burials started to change in the Czech Lands: instead of burials in remote areas, they were happening closer to city centres. From the 12th century onwards, we can notice an increase in churches with cemeteries. Thus, cemeteries became a common part of towns and villages [2]. 
Medieval cemeteries have been referred to as public spaces which can serve as marketplaces [3]. But the idea of the bustling marketplace in a church cemetery is at odds with everything we know about burial and respecting the deceased, However, before that, both in Europe and elsewhere in the world, a cemetery stretching around the church in the middle of the village could have become a marketplace at times if there were no other alternatives due to the lack of free space. Similarly, early Christians that hid during times of persecution in the Roman catacombs had to come to terms with the fact that their meetings and ceremonies were taking place in burial sites. Otherwise, medieval Europeans avoided graveyards and only visited them with a mixture of respect and fear, even though they had more frequent and intensive experiences with death than we have today [4].

Cremation was brought back to society by various activists. The main credit for this belongs to the organised movement 'Supporters of Cremation' which began in the middle of the 1870s. Cremation associations, established during this time in Germany, Great Britain, the Netherlands and the USA, sped up the reintegration of cremation when it became possible to transform wishes into reality - the opening of the first modern crematorium (in 1876 in Milan and Washington after the changing of medical laws) [5].

In 1782, Josef II reformed the funeral business by creating the Dvorský decree which influenced burial in the former Austro-Hungarian Empire, which contained the Czech Republic (then known as Czechoslovakia). Among the most important regulations which influenced the development and planning of cities and towns in the Czech Republic was the establishment of cemeteries away from urban centres. After eight centuries, graveyards cease to be a part of the community. This is also the time when the law dictating the compulsory building of walls around cemeteries was approved as well as the recommendation to separate cemeteries from villages by a forest, hill or river [6]. Thus, around European cemeteries walls were built, separating the worlds of the living and the dead. This law still exists in Catholic circles. Calvinist and Lutheran cemeteries in Holland and Scandinavia are not normally surrounded by fences and graves remain unmarked. However, Catholic cemeteries, as well as public cemeteries in countries with Catholic tradition, are clearly fenced, with marked grave sites and eye-catching monuments [4].

Over time, some cemeteries approached towns due to the development of built areas, and in some cases, they even became a part of them again, this time in peripheral suburbs rather than urban centres. However, many of them have remained isolated in areas that least affect the surrounding public spaces, and that are least affected by surrounding public spaces.

It is therefore questionable whether the removal of cemeteries from urban centres is the right thing, or whether we should find ways to integrate cemeteries back into towns and to make people more aware of their existence. Given the increase in vandalism and the lack of interest in some of cemeteries the answer is clear: only those which are still functioning today and have something to offer a visitor should receive the public and religious interest which they deserve either as a final resting place or because there are representative of the rich sepulchral art of the past.

\section{NICE: THE MONASTERY CEMETERY OF CIMIEZ}

The Monastery Cemetery of Cimiez in Nice is situated on a hill overlooking the sea. In the neighbourhood, there are the old Roman ruins and a park. The cemetery was founded alongside the building of the monastery, which boasts a garden full of flowers. This wonderful cemetery is filled mainly by chapel graves, which also create the cemetery wall on the north side. The graves are located next to each other along the main paths, shadowing the terrain. We enter the cemetery at the monastery and follow along one circular path, and another perpendicular path lined with graves joins it. The cemetery as a whole does not have 
any dominant features; each Chapel Tomb is a dominant item on its own (Fig. 1). Some tombs are leaning on the monastery wall and therefore look more significant. Thus, the monastic wall here is also a dominant feature, but it competes with small, detailed white graves. The cemetery has a dominating exterior and the cemetery metal gate acts as a small door; however, after you cross the border to the church, it immediately takes a step back and we find ourselves in a majestic place.

The cemetery is divided into two floors: one of them is at the entrance to the monastery and tin the direction of the parking lot and the other is slightly lower, where it is possible to walk around the monastery and gardens. Each section is visibly separated: a monastery with a fitted marble room close to it, ordered with longitudinal paths, along which you can walk into the green area of gardens with a view of the entire city and the sea (Fig. 2). The cemetery itself is defending its place as much as the terrain has been allowing, on one side it is limited by the cemetery walls, behind which you can see a parking lot. On the other side is sharply

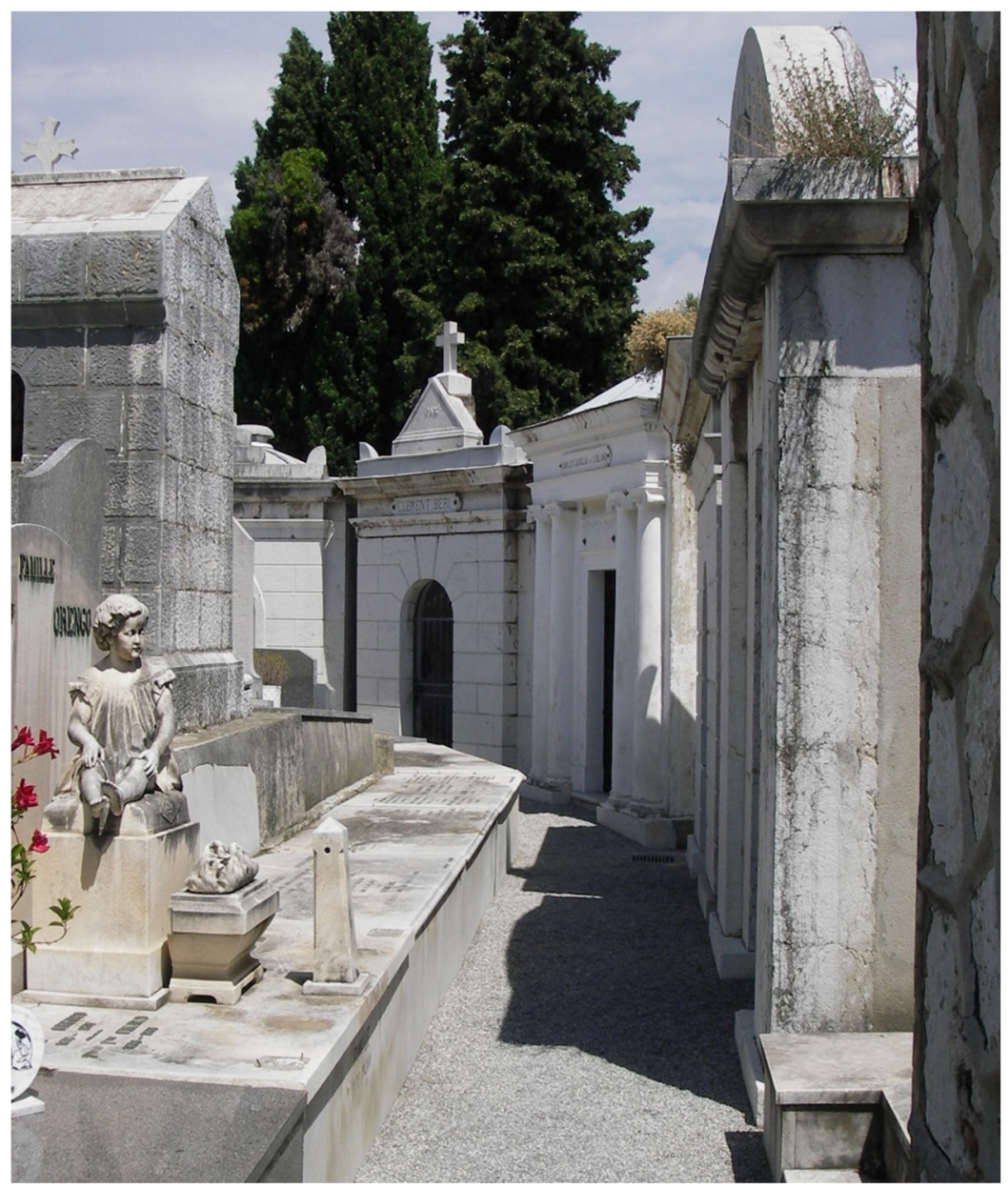

Figure 1: Chapel graves in the cemetery in Nice around the outer peripheral cemetery wall. (Source: Ivona Dlábiková.) 


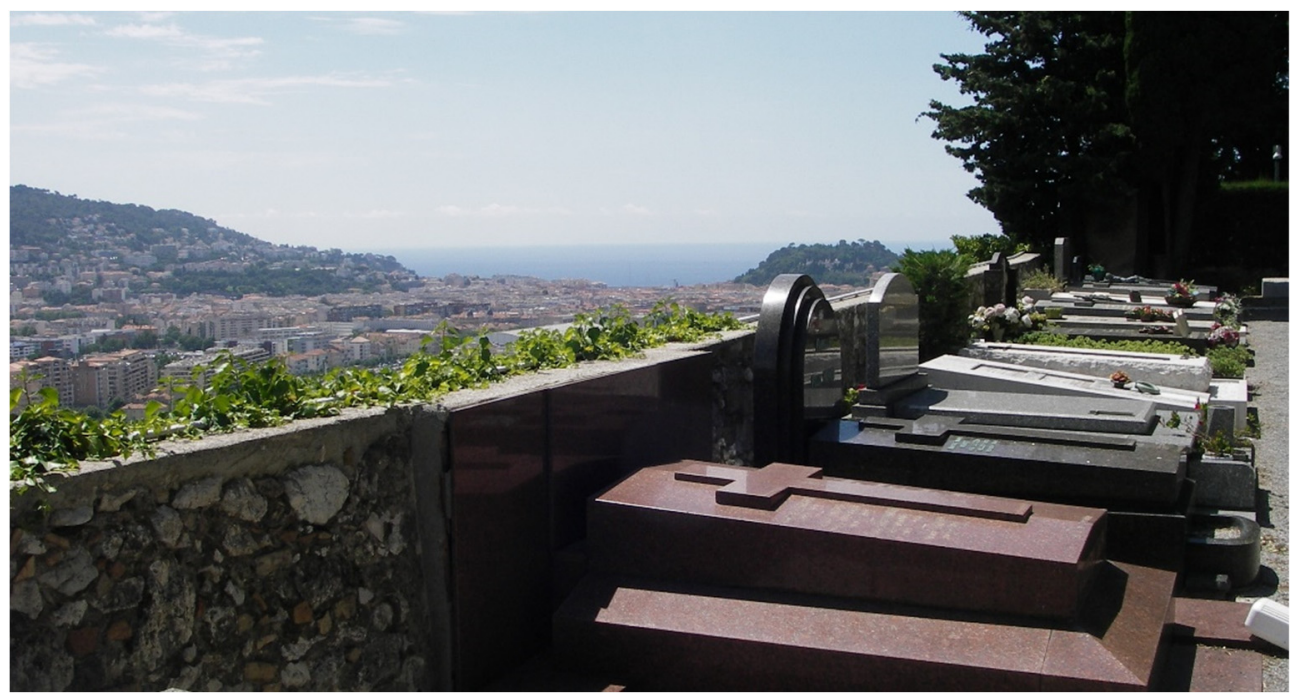

Figure 2: Views of the sea from the cemetery in Nice. (Source: Ivona Dlábiková.)

sloping ground from the side by the monastery wall to the road, however it is not losing any of its value. Its white marble interior with beautifully sculpted statues and concrete paths gives a sense of purity and timelessness. There are no trees or grass: every square inch is used as part of the graves, plinths, cornices, steps and gravestones. In 'The White City', Henry Matisse, a well-known artist, rests and he has been immortalised by The Museum of Henry Matisse, just near the cemetery. We can also see little spires from the palace of Queen Victoria from the cemetery, dating back to the days of the Belle Époque from which the period of her government was derived and where a considerable part of the construction of the city originated. The Palace, called Regina by the local inhabitants, is formed by the original cluster of homes, united into one complex with the same front. Currently, they are luxurious private apartments with a sea view and a private swimming pool.

The part of the town of Cimiez where the cemetery is located is very old; the Colosseum, which is still there, comes from the Roman times and it is said to be the smallest amphitheatre in France, with a capacity of 5,000 spectators. Once, it served only in the town of Cemenelum where the Roman baths were. Only the excavations of these places were preserved can be found in the Archaeological Museum there. This entire district with the graveyard, ruins of the Roman baths, a small amphitheatre, a palace, a park, the museum of Henry Matisse and, at the edge the monastery, a cemetery with a garden all stretch high above the city.

From the gardens, you can see the centre of Nice and the acropolis of the former castle called "Castle Hill" protruding from the coast. From this place, you can see almost all parts of the city and its borders, which are shown by the steep hills. This district once was a village, but today it is a part of the town of Nice, connecting with the centre via a long boulevard with a road lined by trees in the residential area descending down to the wider centre. This was built at the time of the reconstruction of Paris following the example of Haussmann. The wide boulevards and extensive promenades along the coastline called Promenade des Anglais were then created. One side is defined by the faces of the residential blocks and on the other side there is stony beaches and a view of the horizon over the sea. The town of Nice also has a part called Old Town Vielle with the building of the court and the building of the opera 
house, which was burned down and then rebuilt in 1881. This part is full of salespeople in shops and a market with domestic crops. The newer construction is linked to the old town by a promenade along the Paillon River which flows under cobbled paths and a park. From the other side, the old town is regressing into the Castle Hill. The castle is no longer there, only the foundations from the days of Celtic and Roman settlements remain. Today, there are gardens with a view and also the castle and Israeli cemetery. These two cemeteries are located near to the centre of the town, although they were brought up to the height of the acropolis. Otherwise, there are a further thirteen cemeteries mostly adjacent to the part of the church in the suburbs. The area is mountainous and the town is surrounded by the Alps. In the framework of the town the cemetery in the monastery in Cimiez is on the borders, but it has good contact with it because of its high position. It looks as if it is watching the life of the city from a distance.

Its location is multiplied by the surrounding excavations and buildings. Thus, it occupies an honourable place over the city like the cemetery on Castle Hill. It is therefore obvious that our ancestors used to bury the dead in important places. Certainly, this was due to the specific coastal areas where it would not have been appropriate to put a cemetery, due to the risks that come with being near water. Practical reasons certainly play a big role there, however we can see great differences in understanding the cemetery as the stone city, next to which there is an independent garden and a park unlike the cemeteries in Central Europe, where they themselves are designed as the place with trees, grass and flowers, unifying a park, garden and a cemetery in one. Such a unity creates a certain space between the individual deceased; it mirrors the sacred groves established by the Slavs where they used to bury their deceased [7]. In Europe, this tradition has been encountered again in the form of forest cemeteries [8]. On the other hand, the cemetery in Cimiez in Nice is like a room where you can go and see the deceased; it corresponds to the concept of "living forever". A room for the rest of the deceased, a room for a walk through a garden with a generous view and a monastery for prayer. These separate parts then form a single cemetery, which if one was to go through, they would feel the journey and the sequence of it.

\section{VIENNA: MEIDLING CEMETERY}

The cemetery in Meidling can be seen directly from the train station. It is not separated by an opaque wall, but instead by the fence, through which you can see gravestones (Fig. 3).

In the vicinity, there are mainly residential houses that interact with the garden of silence which they are facing. It is crowded by the railways and a road. The composition of the cemetery is a regular network of moon-shaped passageways with a middle axis ending at the train station. The height of the cemetery does not change, therefore, the focus of the cemetery cannot be recognized from eye level. It is only clear from the guide at the entrance because of poor organization, meaning that it does not show the strict layout at first glance. The city of Vienna is built on a plane and the Danube river flows through it; therefore, the distances between them are longer and the city can afford to be generous with space. There are 55 graveyards in Vienna, but not one of them is situated in the heart of the city. They are located on the outskirts and are conceived as a place with trees, flowers and graves. For example, the main cemetery of Vienna called Zentralfriedhof has a number of areas which rather resemble a meadow than a cemetery. Each space can be reached by car or by bus.

Its area is so vast that it was important to build roads inside the cemetery. It has a double axes symmetrical composition, in the middle of which there is a monumental chapel in a Jugendstil or Austrian Art Nouveau equivalent style (Fig. 4), which you can reach from the main entrance by a broad alley lined with graves of famous Austrians (Amadeus Mozart, Johannes Brahms, Johann Strauss, Franz Schubert, Ludwig van Beethoven, etc.). The 


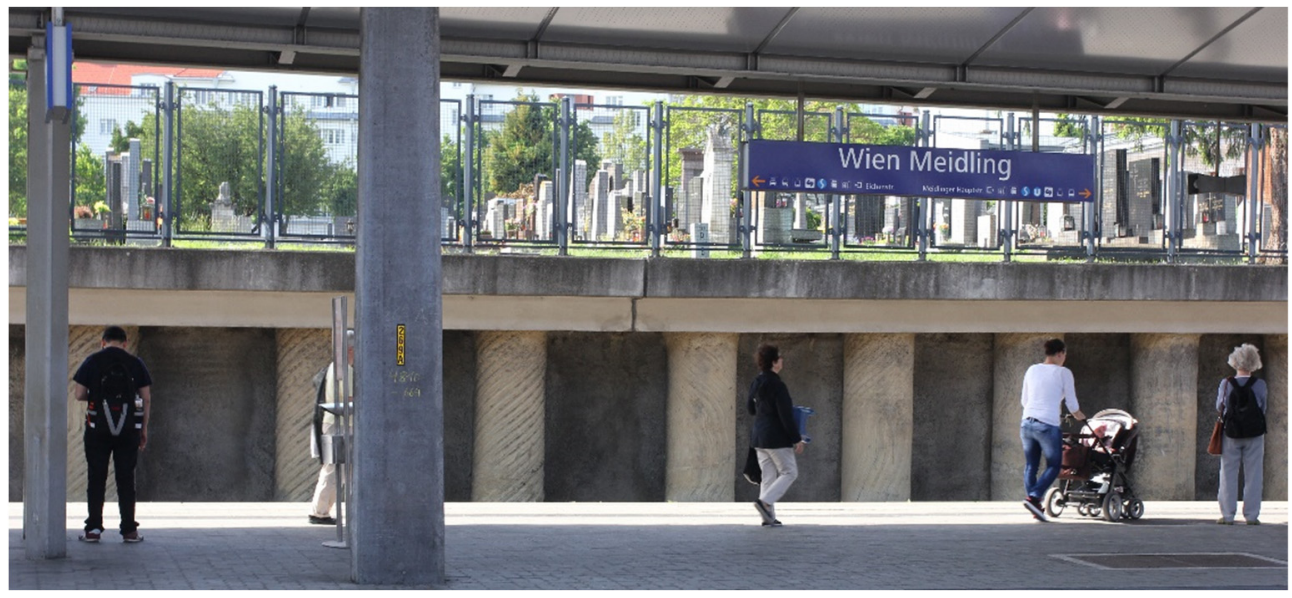

Figure 3: The Cemetery in Meidling directly next to the train station. (Source: Ivona Dlábiková.)

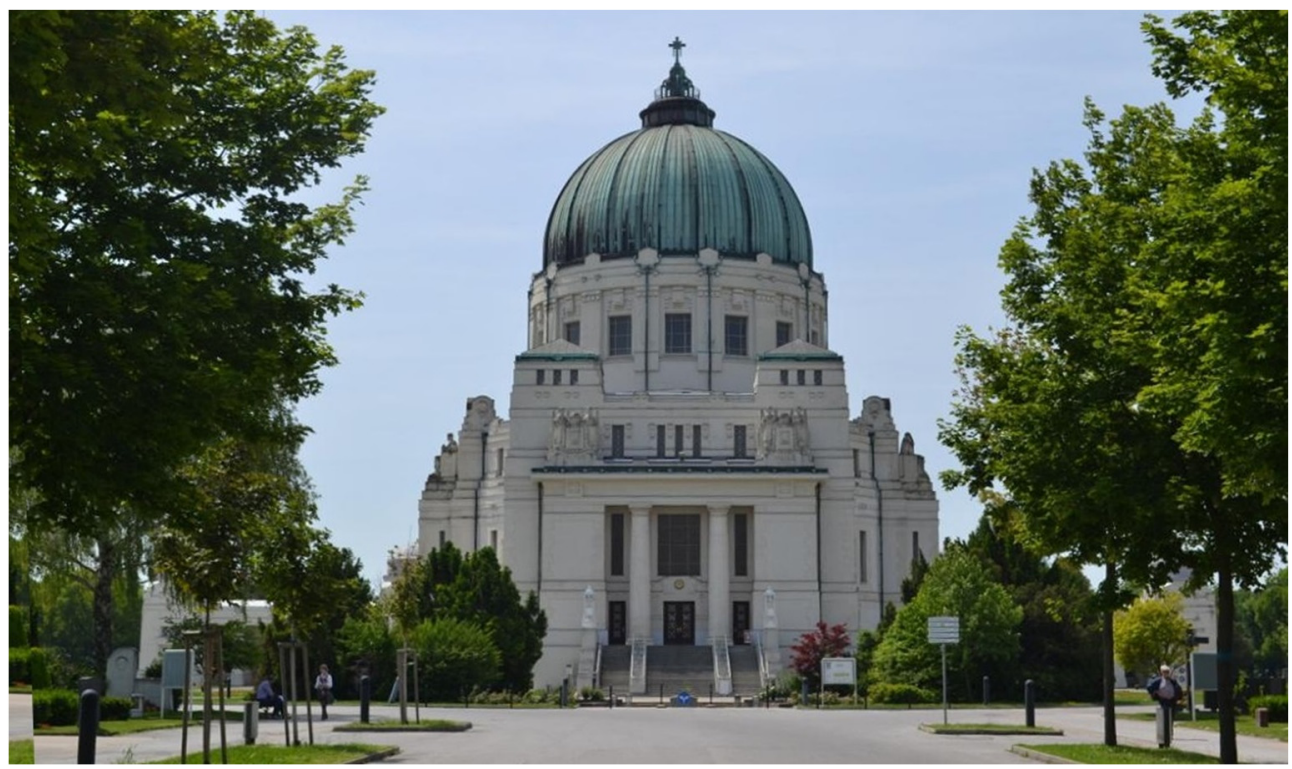

Figure 4: The chapel in Vienna in Art Nouveau style, Zentralfriedhof, Vienna. (Source: Klára Froliková Palánová.)

generous areas between graves serve as space for future burials. The chapel itself dominates due to its height, and it is visible even from the more distant parts of the cemetery. We can always know what awaits us at the end of the journey to the centre of the cemetery. But the cemetery is located at the edge of the town, so the name 'Central' then loses its significance in relation to the city. The Cemetery in Meidling is situated in the residential area with a large park and is close to the Schönbrunn Palace Gardens, which are then connected to the 
Ringstrasse or Wiener circuit by a boulevard. Thus, it is still connected to what is happening and is linked to the city. It is an ideal place for relaxation and waiting for train connections as well as being a garden in the middle of a densely populated city. There is almost no cemetery wall: the boundary between the world of the living and the dead is disappearing. The cemetery is becoming more of a public space, but it will probably never become one in full. In the majority of European cemeteries there are certain restrictions, therefore, the cemetery has never been and never will be a common part of public space. However, it belongs to the wider area of the town or municipality as a place which must continue to retain its uniqueness [4].

\section{PRAGUE: VYŠEHRAD CEMETERY}

Last but not least, the cemetery in Prague at Vyšehrad is significant. The cemetery is a part of the district of the original seat of Czech princes, which was used from the 9th century before the construction of Prague Castle began. High above the Vltava river there is a hill (comparable to the Castle Hill rising from the sea in Nice), where you can find the Basilica of St. Peter and Paul (after the last reconstruction in the neo-gothic style), next to which a cemetery containing big names can be found.

The cemetery wall is formed of an arcade corridor with tombstones on three sides. The cemetery is composed of irregular paths. The main path seems to lead along the perimeter wall with arcaded walkways, along which the visitors walk intuitively and which leads to Slavín. Slavín is the conjoint tomb of the greatest personalities in Czech culture. The impression from this sculpturing is enhanced by slightly ascending terrain and thus, the cemetery has its own dominant feature. As the dominant feature can be seen as well as the church (Fig. 5), which is adjacent by one wall with the cemetery, we guess there is kind of border with the other world of the church. The cemetery is adjacent to the Vyšehrad Orchads decorated sculptures. In the vicinity of it there is also the Romanesque Rotunda of St Martin. The Vyšehrad premises are surrounded by a rampart which ends with the gate Leopold or Cihelná. These monuments are proof of the ancient times and connect the past with the present. Once again, the element of water appears: the Vltava river washes the feet of the spur on which Vyšehrad is situated. The river still flows; it never stops, much like the neverending cycle of life. Vyšehrad is one of 29 cemeteries located outside of the city centre, with the exception of the Old Jewish cemetery. The largest and the most essential (next to the Vyšehrad and Vinohrady cemetery) is Olšany cemetery in which visitors feel as if they were in a different world due to its peace and quiet (Fig. 6), in contrast to the sound of the traffic behind its walls. Mothers with prams go for walks there and relax on a bench; managers in suits come to eat their lunch and break up the scenery from just looking at the green trees. the cemetery is surrounded by a wall on one side, lined by chapel graves on the other side by the columbarium. The cemeteries in Prague are places with trees, flowers and graves, but most of them have an wall separating themselves from the rest of the world; they are sovereign units and enclosed gardens of silence. They are predominantly on the ground plan of the regular streets and paths, and are lined by graves which are very close to each other, according to the Austro-Hungarian establishment of cemeteries. The main axis is in the shape of a cross and the regular plan is only disrupted by diagonals paths. On the street corners and along the central axis there are graves of significant personalities.

Vyšehrad Cemetery is located on a hill out of the main routes for walking or transport, is built on a pedestal as a place for important personalities and is enriched by numerous sepulchral arts. It is an exceptional location and tourist destination. The significance of the place means that is is removed from the centre of the town and in this case, it is correct. On the other hand, Olšany cemetery in Prague is in close proximity to walking and transport 
routes, shopping centres and administrative structures. The space is limited by walls, which isolates it from the rather close public space. It is a place for relaxation, thinking, meditation and prayer. The management of the cemetery have tried to link the two worlds by opening a café and gift shop, and a map of the graves of famous people was made.

On the other hand, there are the cemeteries on the borders of the capital city, intended purely for burial, which are now disappearing, are perishable and, given the high degree of cremation in Prague (98\%), they no longer fulfil their purpose. How do we aim for the future? How do we re-integrate them into the public space of the city?

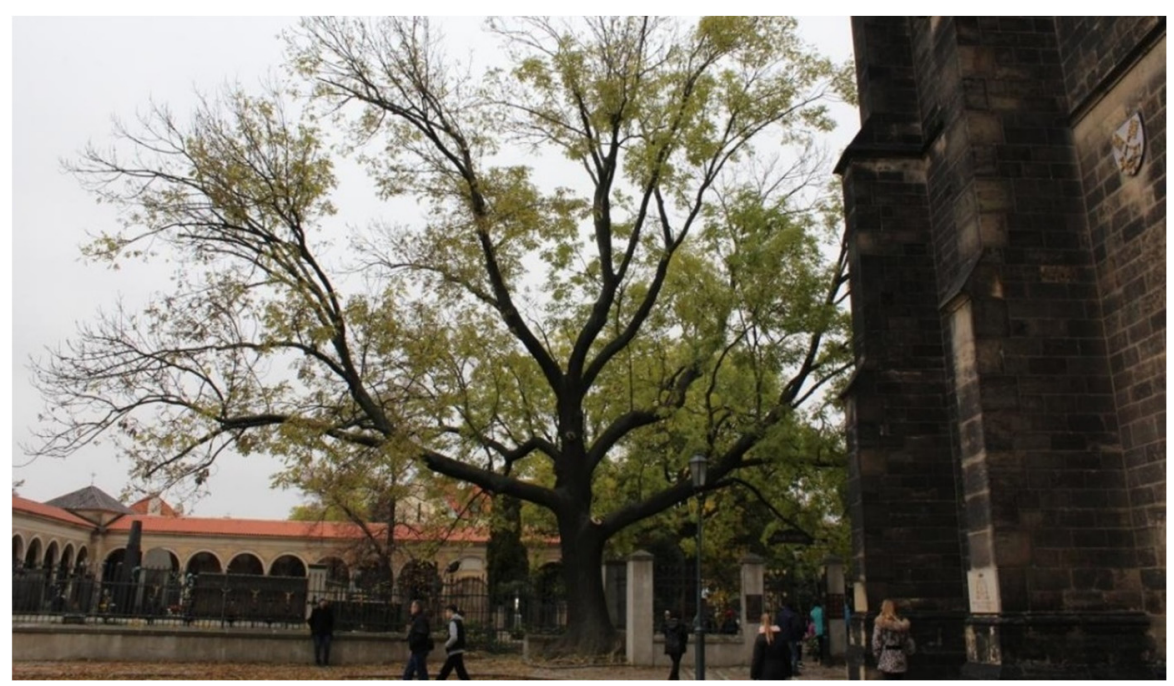

Figure 5: The arcade corridor and the base of Basilica of St Peter and Paul at Vyšehrad. (Source: Klára Froliková Palánová.)

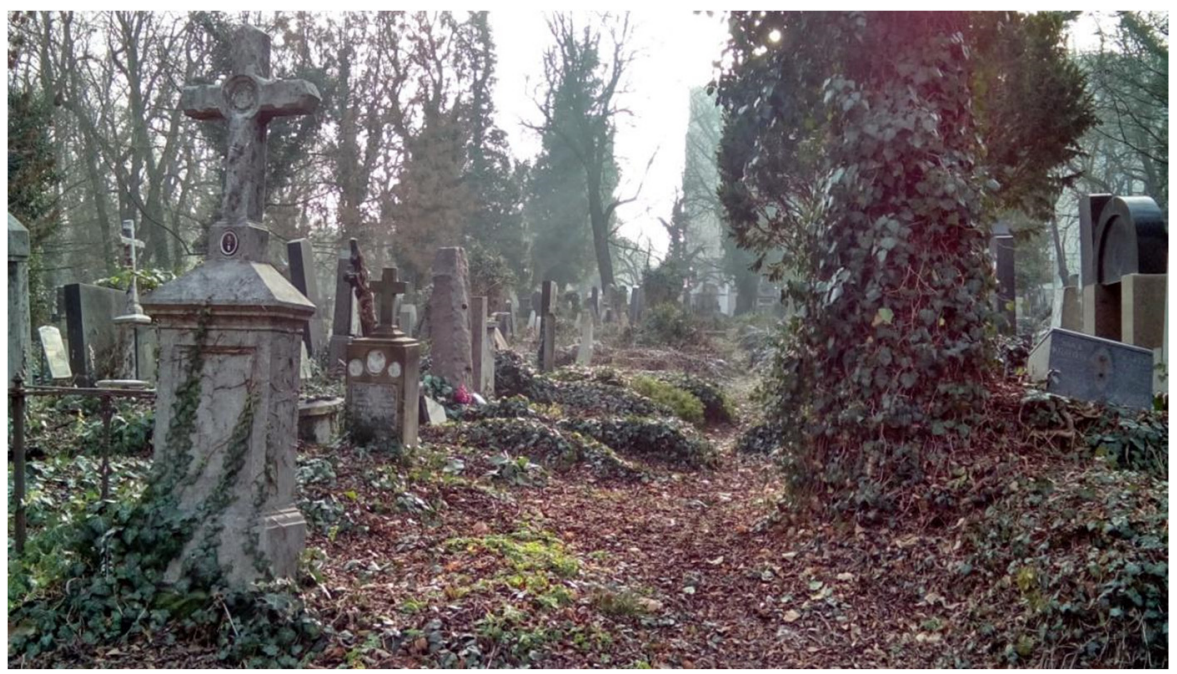

Figure 6: Olšany cemetery, less frequently attended part, Prague. (Source: Klára Froliková Palánová.) 


\section{SUMMARY}

Burial is an integral part of every society. The growth of cemeteries depends entirely on the deceased. The mentality, ceremonial rituals, method of burying (inhumation or cremation) and their symbolism are largely influenced by time, place and also by various events such as the development of human activities, for example warfare [9]. From the 18th century, Europe experienced large changes in the health sector. The improvement of hygiene conditions and nutrition led progress in medicine to a significant reduction in mortality [10]. People started to die in hospitals, not at home as it used to be before. Thus, death alienated us. The phenomenon of death appears to be independent of the time [11]. It will always be here, only our view on it is changing. The considerable influence on the current behaviour in society means that the desacralization of burying has increased in the course of the last century. That is why it is necessary to look for new directions of cemeteries so that they would be a fullyfledged part of our cities even in the current century.

Some of the selected cemeteries, like many others, e.g. Vyšehrad, part of Olšany cemetery and Meidling, and also the cemetery in Nice, work as fully-fledged parts of the urban areas, yet they are enclosed by walls and have limited opening hours. From the point of view of the public space: if we can see it according to the definition of a "non-personal part of urban settlements, where people meet who do not know each other personally or are known only categorically" [4], we find out that this model of cemetery fulfils that. However, if we add the sociological definition, which adds a condition of legal access for all that is under the normal conditions [4], we come across gateways which close the cemeteries after the opening hours. This is the difference between Lutheran and Catholic cemeteries at present. According to the condition "the loss of public positions" (Kovár et al. [4]), which the religion in the Czech Lands recorded in the last 50 years and then consequent high rates of atheism which have caused a change of the moral values of society, it cannot be dealt with differently. Other deterioration of our cemeteries appeared with the production and distribution of monuments and frames and even entire tombs made of synthetic stone with a very imperfect shape, colour and processing, especially in its early days, but conspicuous even with the best processing, which is not substantially different in price from natural stone [12].

Whereas the cemeteries are not public spaces in the truest sense of the word, they are an essential part of an urban area [4]. The experience shows that people visit cemeteries no matter what their location (see displaced Vyšehrad cemetery, or the cemetery remote from the city centre in Nice), but the likelihood of visits depends on what they can offer. Former Director of Administration of Prague Cemeteries, Martin Červený, describes the situation as follows: "Because of the high number of cremations there is decreasing interest in grave places. Partly the function of cemeteries is changing. People go there for a walk or to seek quiet" [13]. So, the whole image of the cemetery is changing, gradually there is a declining number of graves and the premises are becoming more like a city park which people go to for a walk. As inspired by the interest in sepulchral art, funeral/ cemetery tourism is also growing. As an example, the aforementioned Vienna Central Cemetery, where buses full of tourists arrive who tour perfectly decorated gravestones of famous personalities with a map. A similar trend is developing at the cemeteries in the Czech Republic. For a long time Vyšehrad cemetery in Prague worked similarly (where e.g. the Čapek brothers are buried, as well as the opera singer Ema Destinnová and also Milada Horáková, who have symbolic graves there). A great potential is laid in Olšany cemetery due to the position in the city, but also due to the extraordinary sepulchral art and the personalities that are buried there. The Administration of Prague Cemeteries (SPH) have already worked out a plan for their reconstruction and they have already established the educational trails around and about the cemetery. Furthermore, the Administration of Prague Cemeteries (SPH) wants to build a café, 
for example, which would serve not only to mourning guests, but to visitors and tourists. A similar one already operates in the Berlin Kreuzberg. Prague Lesser Town cemetery, after a total revitalisation, launched guided tours [13].

Many cemeteries, however, got stuck in development, lacking an imaginary half-step towards the world of the living. This may be just the restoration, revitalisation, revival - such as the building of a new background premises not only for the maintenance of the cemetery, but for visitors too. Each cemetery can be proud of its long history, the prominent location or the quantity of personalities, even though that was not their original purpose. Not country, but mainly urban cemeteries (cemeteries in the larger cities) "suffer" from lack of interest from a secularised society, law attendance and subsequent decline which is an attractive space for vandalism (Fig. 7). Neglected companies are bad reminders of the present day.

There seems to be a fundamental need to rethink their future direction and if they no longer fulfil their purpose, they should be converted gradually to a park with reference to their original purpose. To maintain the piety of the place, they should display the names of the dead into the walls or tiles and expose artistically valuable gravestones. This idea is offered for example at the cemetery in Ostrava-Hulváky which has not been used for burials and has not allowed ash storage since the 1950s. Its original plan was disrupted by its partial cancellation and substitution of the bustling street and new building of Vítkovice Ironworks. If, however, the unceasing interest is recorded, it would seem to be more than appropriate to complement the existing cemeteries with the possibility of new forms of burials, especially ash storage. In a country with an abnormally high rate of cremation and with a high number of crematoria as well as cremations, this seems to be a further possible way to maintain the current necropolis, therefore keeping their original purpose. The construction of columbarium, graves for storing the urns or spaces for epitaph plates and of memorial scattering meadows which are enjoyed with great interest allow continued functioning of the premises of cemeteries and convert them into the 21 st century.

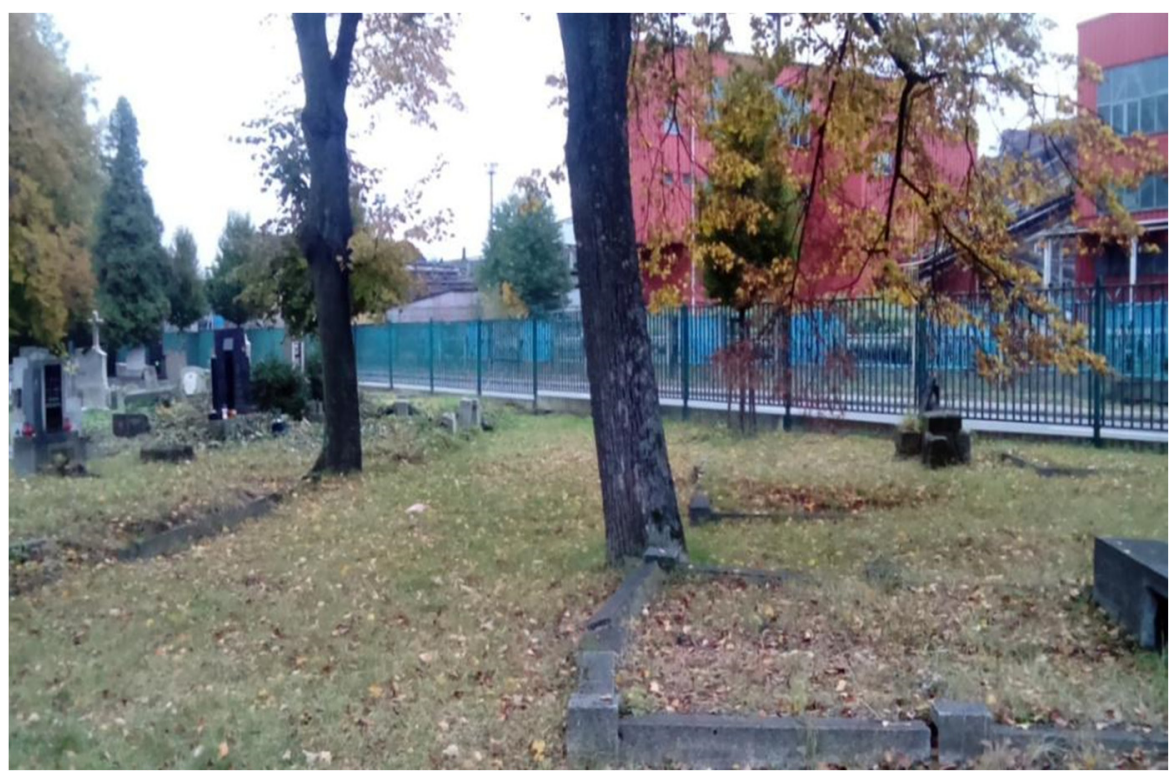

Figure 7: The current state of the cemetery in Ostrava - Mariánské Hory, the view of the Vítkovice Ironworks through the cemetery. (Source: Klára Frolíková Palánová.). 


\section{CONCLUSION}

The sanctity of the place and its meaning today, which the Roman Catholic Church has been spreading for centuries, evokes an exceptional experience when entering the necropolis. Piety is not distorted, even by the funerals and graves of extraordinary personalities, it is supported as it provides a new sense of cemeteries for today's society, particularly at The Central Cemetery in Vienna, The Olšany in Prague, in Nice and at the Vyšehrad. The tribute in treating the past as well as the present supports cultural, but also national, sentiments and helps to educate younger generations. The awareness that remains in their subconscious helps to eliminate vandalism which often occurs at the peripheral cemeteries.

The renewal of the necropolis with facilities for visitors also proves beneficial, particularly in more distant locations. If the place for the dead is combined with the needs for the living, there is a positive interaction and experience of an exceptional moment when "visiting" our loved ones, as well as when relaxing and meditating. In these moments, a wall is not an obstacle, but defines it as a sacred place, allowing for warning and instruction from the different authorities which look after that location. Increasing the quantity of gates will help the accessibility of the area without building a barrier in the city, and, at the same time, more sites will be available, even those which are normally ignored by the visitors (the oldest part of Olšany cemetery). Last but not least, in the cemeteries which do not serve to the funeral tourism only and are not in an appropriate location for walks, there is a need to supplement them and to ensure the new forms of burial. There is the possibility of storing ashes so that they can continue to fulfil their function for which they have been set up for originally, such as the establishment of columbarium in unused chapel tombs, the establishment of the memorial scattering meadows in locations of defunct graves, or allowing urn storage in the area of the existing tombs.

We can take the example of the cemeteries in Nice, where there are separate places for the deceased and then there is another "area" in the form of a garden or a park; one using this additional element can get away from the death which is looking at them in the form of gravestones. The graves are then placed one next to the other, unusually dense in comparison with those in Central Europe. The space is given by the garden itself. We can take as an example the cemetery of Meidling because of the courage which is shown by having a location directly next to a railway station that they can live together. We appreciate that it has not been transformed into a park or that they avoided building new premises, as it happens at the time of the rapid construction. It has lived on its own even next to the busy road and fully serves its original function. It is not a directly public space, but it lives within the environment and offers a place for a quiet contemplation away from the busy world. Vyšehrad cemetery has a long history, first a place on the upper position for a stay of princes and today, a place for eternal rest of important personalities. Such a position has been being built for centuries, but we can notice how important places for the living changed to an important place for the dead. The cemetery has literally an exceptional position. Why should the word cemetery evoke abandoned, not maintained, aside and a sad place to most people in society today? With the exception of the country cemeteries in churches that keep their traditions and rules, the urban cemeteries are usually a place which many people do not attend, unless it is the holidays. These are the places without rules, which not kept tidy. The places like Vyšehrad or Olšany cemeteries are the opposite examples. The shelter for the dead is dignified and the living can admire it. The cemetery deserves an important place in today's society.

The cemetery as a unit in a town in the framework of time seems to be stagnant. It is changing slower than the rest of the city, so let us give it more time and space, as with the other buildings; it used to be here before and will stay longer than we will. 


\section{REFERENCES}

[1] Frolíková-Palánová, K., Kovár, J. et al., Burying as Part of Life in the European Context. Architecture in perspective VI., Germany: TTP Ltd, pp. 39-43, 2014.

[2] Nešporová, O., About death and burying, The center for study of democration and culture, p. 226, 2013.

[3] Ariés, P., The hour of our death., Prague: Argo, p. 86, 2000.

[4] Kováŕ, J., Peřinková, M., Špatenková, N. et al., The cemetery as a public space, Ostrava: Gasset \& VŠB-TU Ostrava, pp. 61-62, 2014.

[5] Association of friends of cremation. Online. www.pohreb.cz/spolecnost-pratel-zehu. Accessed on: 30 Jul. 2017.

[6] Kotrlý, T., Funeral service, the legal ensure of piety and dignity of human remains, Linde Prague, p. 171, 2013.

[7] The source, regional newspapers of civic association Genius Loci, Sacred groves, Online. pramen.info/c/1305/posvatne-haje.htm. Accessed on: 20 Jun. 2017.

[8] The forest of memories. Online. www.lesvzpominek.cz. Accessed on: 10 Jul. 2017.

[9] Moreaux, P., Birth, life and death of cemeteries, Le Bouscat: L'Esprit du temps, p.7, 2009.

[10] Špatenková, N. et al., About the last human things, Prague: Galén, 2014.

[11] Ariés, P., The western attitudes toward death: From the Middle Ages to the present, London: John Hopkins University press, p. 1, 1974.

[12] Almer, J., The need for a new adaptation of Prague cemeteries, Prague: Pensions of the capital city of Prague, 1928.

[13] The date on cemetery? Prague wants to have the coffee bar between graves and more benches. Online. praha.idnes.cz/zmeny-na-prazskych-hrbitovech-det-/praha-zpravy. aspx?c=A141215_2124492_praha-zpravy_mav. Accessed on: 20 Jul. 2016. 